\title{
Korumak ya da Korumamak? Robotik Radikal Prostatektomide Mesane Boynu*
}

\author{
To Spare or not to Spare? Bladder Neck and Robotic Radical Prostatectomy
}

\author{
Murat Keske', Abdullah Erdem Canda² \\ ${ }^{1}$ Kayseri Șehir Hastanesi, Üroloji Kliniği, Kayseri \\ ${ }^{2}$ Koç Üniversitesi, Tıp Fakültesi, Üroloji Anabilim Dalı, İstanbul
}

Geliş tarihi (Submitted): 28.11.2018 Kabul tarihi (Accepted): 25.04.2019

\section{Yazıșma / Correspondence}

Dr. Murat Keske

ORCID: 0000-0001-6591-4506 Kayseri Şehir Hastanesi Üroloji Kliniği Kocasinan 38010 Kayseri

E-mail: muratkeske@yahoo.co.uk Tel: 05426620882

\section{(c) (1) (\$)}

Bu eser Creative Commons AtifGayriTicari 4.0 Uluslararası Lisansı ile lisanslanmıștır.

\section{Özet}

Amaç: Mesane boynu korunan ve korunmayan hastalarda robotik radikal prostatektomi (RARP) sonuçlarının karşılaştırılması.

Gereç ve Yöntemler: Tek cerrahın gerçekleştirdiği ve ilk 50 vakanın öğrenme eğrisi nedenli çalışma dışı bırakıldığ lar alındı. Grup 1 (mesane boynu korunan, $\mathrm{n}=141$ ) ve Grup 2 (mesane boynu korunmayan, $n=73$ )'de sırasıyla ortalama hasta yaşı 64.4 ve $65.2(\mathrm{p}=0.396)$, serum PSA düzeyi 12.1 ve $12.6(\mathrm{p}=0.846)$, bilateral nörovasküler demet (NVB) koruma $89(\% 63.1)$ ve 53 (\%72.6) ve unilateral NVB koruma 32 (\%22.6) ve 14 (\%19.1) hasta idi.

Bulgular: Grup 1 ve 2'de sirasiyla ortalama prostat ağırlığ 56.03 ve 72.9 gr ( $\mathrm{p}=0.001)$, posterior rabdosfinkter rekonstrüksiyonu (rocco sütürü) oranı \%11.3 ve \%9.6 ( $\mathrm{p}=0.694)$, ortalama konsol süresi 154.2 ve 164.3 dakika $(\mathrm{p}=0.164)$, intraoperatif kan kaybı 91.8 ve $103.7 \mathrm{cc}(\mathrm{p}=0.098)$, hastanede yatı̧s süresi 4.01 ve 4.04 gün $(\mathrm{p}=0.879)$, üretral kateter çekim süresi 8.6 ve 9.5 gün ( $\mathrm{p}=0.04)$, pozitif cerrahi sınır oranı 43 (\%30.4) ve 19 (\%26.0) $(\mathrm{p}=0.494)$, ortalama çıkarılan lenf nodu sayılar1 13 ve 14 ( $\mathrm{p}=0.602)$ idi. Postoperatif 7., 14. ve 21. günlerde sistogramda kaçak olmayan ve üretral kateteri çekilen hasta sayısı sırasıyla Grup 1'de 78 (\%66.1), 37 (\%31.3) ve 3 (\%2.5); Grup 2 de 61 (\%83.5), 10 (\%13.6) ve 2 (\%2.7) idi. En az 1 yıllık takip süresi olan hastalardan $(n=185)$, erken kontinans (sonda çekilmesini takiben kontinan) oranları Grup 1 ve Grup 2

\section{Abstract}

Objective: To present the outcomes of robotic radical prostatectomy (RARP) in patients with and without bladder neck sparing.

Material and Methods: A single surgeon series of cases after having an experience of $>50$ procedures were included. Group-1 included patients with bladder neck spared, n=141 and Group-2 included patients with bladder neck not spared, $n=73$. Mean patient age, preoperative serum PSA, bilateral neurovascular bundle (NVB) sparing and unilateral NVB-sparing were 64.4 versus 65.2 years $(\mathrm{p}=0.396) ; 12.1$ versus $12.6 \mathrm{ng} / \mathrm{ml}$ ( $\mathrm{p}=0.846) ; 89$ (63.1\%) versus 53 (72.6\%) and $32(22.6 \%)$ versus $14(19.1 \%)$, respectively in Groups 1 and 2.

Results: Mean prostate weights were 56.03 gr and 72.9 gr in Groups 1 and 2, respectively ( $\mathrm{p}=0.001$ ). Rocco suture was performed in $11.3 \%$ and $9.6 \%$ of Groups 1 and 2, respectively ( $\mathrm{p}=0.694$ ). Mean console time, intraoperative blood loss, duration of hospital stay and urethral catheter removal time in Groups 1 and 2 were 154.2 vs $164.3 \mathrm{~min}(\mathrm{p}=0.164)$; 91.8 vs $103.7 \mathrm{cc}(\mathrm{p}=0.098) ; 4.01$ vs 4.04 days $(\mathrm{p}=0.879)$ and 8.6 vs 9.5 days $(\mathrm{p}=0.04)$, respectively. Positive surgical margin rates were similar (43 (30.4\%) vs $19(26.0 \%)$ in both groups $(\mathrm{p}=0.494)$. Mean lymph node yielded were 13 vs 14 in Groups 1 and 2, respectively $(\mathrm{p}=0.602)$. Cystography on postoperative day7, day-14 and day-21 showed no leakage and urethral catheter was removed in 122 (86.5\%), $15(10.6 \%)$ and $4(2.8 \%)$ of Group-1, and 61

* Bu çalışma, 12-13.Nisan.2018 tarihlerinde İstanbul'da düzenlenen Endourological Society, Symposium on Robotics and New Technologies in prostate cancer isimli toplantıda en iyi 3. poster ödülü almıştır. 
de sırasıly $\% 58$ ve $\% 31$ idi ( $\mathrm{p}=0.001)$. Total kontinan hasta sayıs1 sirasiyla Grup 1 ve 2'de postoperatif 1 . ayda $\% 70$ ve $\% 41$ ( $\mathrm{p}=0.002)$; 3. ayda $\% 81$ ve $\% 60$ ( $\mathrm{p}=0.004) ; 6$. ayda $\% 92$ ve $\% 82$ ( $\mathrm{p}=0.053$ ) idi.

Sonuç: Mesane boynu koruyucu RARP postoperatif erken üriner kontinans kazanılmasında avantaja sahiptir.

Anahtar Kelimeler: prostat, robotik, mesane boynu koruma
(83.5\%), $10(13.6 \%)$ and $2(2.7 \%)$ of Group-2, respectively. Of the available 185 patients, following removal of the catheter, immediate continence rate was $58 \%$ and $31 \%$ in Groups 1 and 2, respectively ( $\mathrm{p}=0.001$ ). On postop 1 st-month, $70 \%$ and $41 \%$ of the patients in Groups 1 and 2, respectively were fully continent $(\mathrm{p}=0.002)$. On postop 3rd-month, $81 \%$ and $60 \%$ of the patients in Groups 1 and 2, respectively were fully continent $(\mathrm{p}=0.004)$. On postop 6 th-month, $92 \%$ and $82 \%$ of the patients in Groups 1 and 2, respectively were fully continent ( $\mathrm{p}=0.053)$.

Conclusion: Bladder neck sparing RARP procedure has an advantage in terms of gaining postoperative early urinary continence.

Keywords: prostate,robotics,bladder neck spare

\section{GiRiş}

Robotik radikal prostatektomi ameliyatının (RARP) lokalize prostat kanseri tedavisinde popülaritesi gün geçtikçe artmakta olup sıklıkla kullanılan bir cerrahi tedavi yöntemi olmaya başlamıştır (1). RARP’n üç boyutlu görüntü, optik büyütme, tremor filtrasyonu sağlaması gibi avantajları vardır (2). Buna rağmen mesane boynu belirlenmesi yoğun adipoz doku varlığı, geçirilmiş pelvik cerrahi, mesane duvarında kalınlaşma, çok büyük prostat volümü ve median lob varlığı gibi nedenlerle zor olabilir. Ayrıca bu aşamada yanlış doku planında diseksiyon yapılmasının (örn. prostat içine doğru veya mesane trigonuna doğru) onkolojik sonuçlarda başarısızlığa veya mesane boyun rekonstrüksiyon gereksinimine neden olabileceğini gösteren çalışmalar vardır (3). Mesane boynu koruyucu teknik, cerrahi sonrası kontinans oranlarını artırmak amacıyla iç sfinkterin korunması mantığıyla bulunmuştur. Birçok çalışmada mesane boynu koruyucu tekniğin onkolojik sonuçlardan taviz vermeden uygulanabileceğine yönelik çalışmalarda tartışmalı sonuçlar elde edilmiştir (4-7). Bu çalışmada RARP s1rasında mesane boynu koruyucu yaklaşım uygulanan ve uygulanamayan hastalardaki cerrahi, onkolojik ve fonksiyonel sonuçlar karşılaştırılmıştır.

\section{GEREÇ VE YÖNTEMLER}

Şubat 2009 ile Aralık 2017 arasinda tek cerrah (A.E.C.) tarafından gerçekleştirilen toplam 264 RARP ameliyatının verileri retrospektif olarak incelendi. Operasyon öncesinde inkontinans tarifleyen, nörojen mesanesi olan hastalar ve öğrenme eğrisini tamam- layana kadar olan, cerrahın ilk 50 vakası çalışma dışı birakildı.

D’Amico sinıflamasına göre orta ve yüksek risk grubundaki hastalara RARP sirasinda bilateral pelvik genişletilmiş lenfadenektomi uygulandı. Tüm hastalara postoperatif 7. gün sistografi çekildi. Üriner ekstravazasyon saptanmaması halinde transüretral kateter çekildi. Ekstravazasyon saptanması halinde sonda çekilmesi için 7 gün daha beklendi ve yeniden sistografi yapıldı. Tekrar ekstravazasyon saptanması halinde ise 21. günde sistografi yapılarak kaçak olmaması durumunda transüretral kateter çekildi. RARP sonrası hastalar; birinci ayda ve sonrasında ilk iki yıl 3 ayda bir takiplere çağırıldı.

Hastaların demografik (yaş, vücut kitle indeksi, serum total PSA düzeyi, prostat volümü), patolojik (Gleason skorları, patolojik tümör evresi, cerrahi sınır pozitifliği), intraoperatif (cerrahi süresince kan kaybı, konsol süresi, nörovasküler demet korunma, mesane boynu koruma, posterior rekonstrüksiyon teknikleri ve intraoperatif komplikasyon) ve postoperatif (hastanede yatış ve kateter kalış süresi, postoperatif komplikasyon) verileri kaydedildi. Ayrıca takip süresi boyunca hastaların adjuvan tedavi alıp almadıkları, fonksiyonel (erektil fonksiyon ve üriner inkontinans) ve biyokimyasal nüks gelişimi gibi verileri de retrospektif olarak incelendi.

Preoperatif ve postoperatif erektil fonksiyon durumu uluslararası erektil fonksiyon indeksi (IIEF-5) ile değerlendirildi (10). IIEF skoruna göre hastalar ağır (1-7), 1lımlı (8-11), orta (12-16), hafif (17-21) erektil 
Tablo 1. Preoperatif hasta karakteristikleri (PSA:Prostat spesifik antijen, VKİ: Vücut kitle İndeksi, ED: Erektil Disfonksiyon).

\begin{tabular}{|l|c|c|c|c|}
\hline & Tüm hastalar (n=214) & Grup 1 (n=141) & Grup 2 (n=73) & P \\
\hline Hasta yaşı ortalama (yıl) & $64.7 \pm 6.5$ & $64.4 \pm 6.6$ & $65.2 \pm 6.5$ & 0.396 \\
\hline Serum PSA (ng/mL) & $12.2 \pm 1.7$ & $12.1 \pm 1.9$ & $12.6 \pm 1.5$ & 0.846 \\
\hline Prostat volümü (cc) & $61.8 \pm 28.4$ & $56.03 \pm 20.2$ & $72.9 \pm 37.3$ & 0.001 \\
\hline Biyopsi Gleason skoru: $\mathrm{n}(\%)$ & & & & \\
$3+3$ & & $20(\% 56.7)$ & $44(\% 60.2)$ & \\
$3+4$ & & $13(\% 9.2)$ & $6(\% 8.2)$ & \\
$4+3$ & & $21(\% 14.8)$ & $10(\% 13.6)$ & \\
$\geq 8$ & & $47(\% 33.3)$ & $19(\% 26.0)$ & \\
\hline Preoperatif IIEF skoru: & & $12(\% 8.5)$ & $9(\% 12.3)$ & \\
ED yok (22-25): $\mathrm{n}(\%)$ & $20(\% 14.1)$ & $17(\% 23.2)$ & \\
Hafif ED (17-21): $\mathrm{n}(\%)$ & $25(\% 17.7)$ & $15(\% 20.5)$ & \\
Orta ED (12-16): $\mathrm{n}(\%)$ & & $37(\% 26.2)$ & $13(\% 17.8)$ & \\
Ilımlı ED (8-11): $\mathrm{n}(\%)$ & & & & \\
Ağır ED (5-7): $\mathrm{n}(\%)$ & & & & \\
\hline
\end{tabular}

disfonksiyon ve erektil disfonksiyon yok (>21) olarak 5 gruba ayrildı. Preoperatif olarak impotansı olan ve operasyon sirasında nörovasküler demet korunmayan hastalar erektil fonksiyon değerlendirmesinden çıkarıldı. IIEF-5 skoru 21 ve üzerinde olan hastalar normal olarak kabul edildi. Erektil fonksiyon değerlendirilirken en az 1 yıl takibi bulunan hastalar ele alındı.

Perioperatif komplikasyonlar modifiye ClavienDindo sinıflamasına (MCDS) göre değerlendirildi (11). İntraoperatif ve postoperatif 0-30 gün içinde gelişen komplikasyonlar erken dönem, 31-90 gün içinde gelişen komplikasyonlar geç dönem olarak sınıflanmıştır. MCDS'ye göre 1 ve 2. derece komplikasyonlar minör olarak sinıflandırılırken; 3, 4 ve 5. derece komplikasyonlar majör olarak sınıflandırılmıștır.

RARP sonrası ardışı 2 PSA düzeyinin $0.2 \mathrm{ng} /$ mL'nin üzerinde olması biyokimyasal nüks olarak kabul edildi.

Fonksiyonel sonuçlardan kontinans, sonda çekilir çekilmez(erken), birinci, üçüncü, altıncı ve on ikinci aydaki takiplerinde değerlendirildi. Hiç ped kullanmayan veya güvenlik pedi kullanan hastalar tam kontinan olarak kabul edildi.

Tüm hastalar mesane boynu korunup korunamamasına göre 2 gruba ayrıldı. Mesane boynu korunan hastalar grup $1(\mathrm{n}=141)$, mesane boynu korunmayan hastalar grup $2(n=73)$ olarak değerlendirildi.

\section{Cerrahi Teknik}

Tüm RARP prosedürleri da Vinci $\mathrm{Xi}^{\circledR}$ robotik cerrahi sistemi kullanılarak tek cerrah tarafından (A.E.C.) uygulandı. Standart olarak RARP vakaları, daha önce tanımladığımız standart transperitoneal teknikle uygulandı (12). Mesane boynu koruyucu yaklaşımda ise Retzius boşluğuna girildikten sonra prostat çevresindeki yağlı doku diseke edildi. Yağlı doku eksize edilmesi mesane boynunun anatomik olarak cerrah tarafindan net bir şekilde görüntülenmesinde önemlidir. Mesane boynu diseksiyonuna başlanırken bipolar forceps ile mesane boynu posteriora retrakte edilerek mesaneprostat bileşkesine monopolar makas ile yüzeyel doku diseksiyonu yapilır. Derin diseksiyon yapilırken bipolar forceps ile üretranın her iki laterali görüntülenir. Üretradan ayrılan lateral dokular monopolar makas ile kesilir. Transüretral sonda ileri-geri hareket ettirilerek üretranın yeri tam olarak görüntülenir ve mesane boynu termal hasarından kaçınılmış olur. Üretra diseksiyonu sirasinda bipolar forceps kullanılarak ince diseksiyonla tüm üretra serbestlenir. Bipolar forceps ile üretra altından geçilerek üretra tam olarak izole edilir. Üretra kesilirken mesane bipolar forceps ile geriye retrakte edilir. Üretra kesildikten sonra posteriorda kalan prostat mesane bileşkesindeki plan disseke edilir. Ardından daha önce serbestlenen her iki seminal vezikül ve vas deferens operasyon sahasina alınır. 

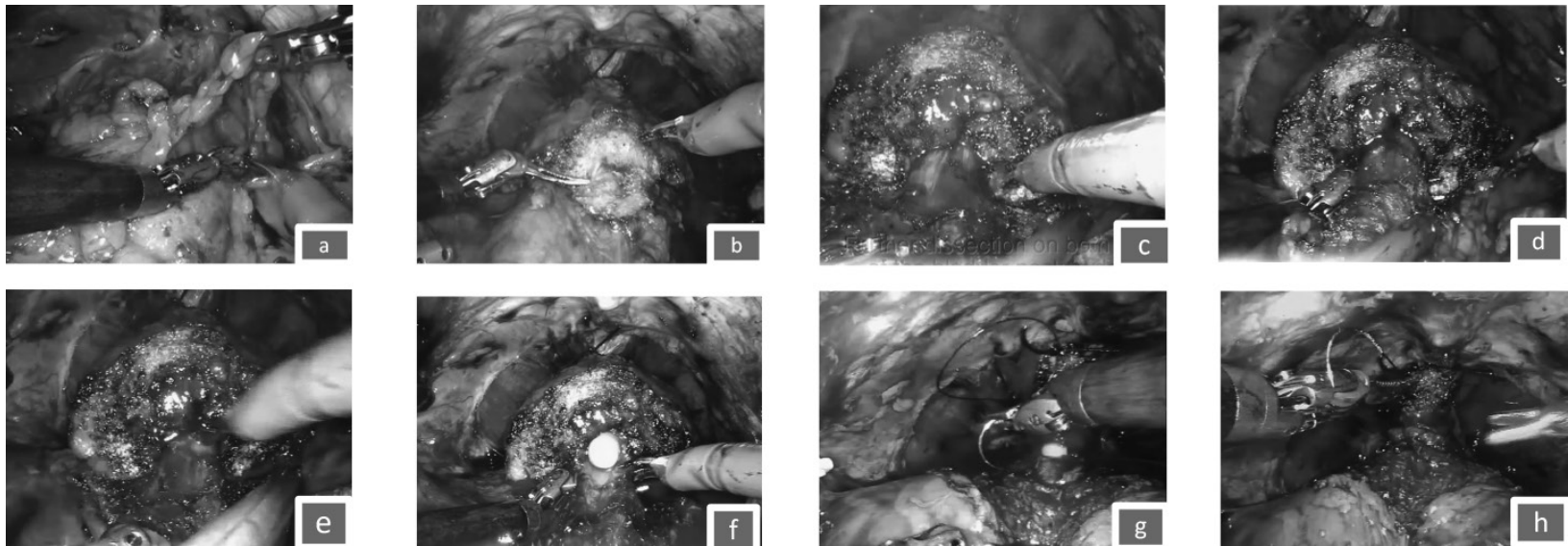

Şekil 1. Aşamalarla robotik radikal prostatektomi sırasında mesane boyun diseksiyonu

a) Periprostatik adipoz dokunun uzaklaştırılması

b) Mesane boynunun monopolar makas ile yüzeyel diseksiyonu

c) Mesane boynunun derin diseksiyonu

d) Bipolar forceps ile üretra serbestlenmesi

e) Üretranın kesilmesi

f) Bipolar forceps ile üretra altından geçilerek üretranın kesilmesi

g) Van Velthoven tipi vezikoüretral anastomoz yapılmas1

h) Su geçirmez vezikoüretral anastomozun görünümü

\section{İstatistiksel Analiz}

Verilerin analizinde SPSS 16 (IBM, Illionis, USA) programı kullanıldı. Verilerin analizinde tanımlayıcı istatistik, gruplar arası karşılaştırmada bağımsız örneklem $\mathrm{T}$ testi veya Mann Whitney $\mathrm{U}$ testi, kalitatif veriler için ise Pearson $c^{2}$, Yates $c^{2}$ veya Fisher's $c^{2}$ testleri kullanıldı. $\mathrm{P}<0.05$ için sonuçlar anlamlı olarak kabul edildi.

\section{BULGULAR}

Preoperatif hasta karakteristikleri Tablo l'de gösterilmiştir. Prostat volümü grup 2 (72.9)'de grup 1 (56.03)'e oranla anlamlı olarak daha yüksek bulunmuştur $(\mathrm{p}=0.001)$.

Peroperatif ve postoperatif hasta karakteristikleri Tablo 2'de özetlenmiştir. Üretral kateter çekim süresi Grup 1 ve Grup 2 için sırasıyla 8.6 ve 9.5 gün $(\mathrm{p}=0.04)$ olarak saptandi.
Modifiye clavien sinıflama sistemine göre perioperatif süre içinde (0-30 gün) grup 1'de 2 minör (skrotal ödem, perivezikal sıvı kaçağı spontan rezolüsyon) ve 1 major (insizyon yeri evisserasyonu) grup 2'de $1 \mathrm{mi}-$ nor (atrial fibrillasyon) and 2 major (postoperatif yoğun bakım ünitesinde izlem gereksinimi) komplikasyon meydana geldi. Postoperatif 31-90 gün içerisinde komplikasyon izlenmedi.

Pozitif cerrahi sınır oranı Grup 1'de \%30.4 ve Grup 2'de \%26.0 ile benzer olarak saptand. ( $\mathrm{p}=0.494)$

Tablo 3'de hastaların fonksiyonel sonuçları gösterilmiştir. En az 1 yıllık takip süresi bulunan hastalarda kontinans ve erektil fonksiyon değerlendirilmesi yapılmıştır.

Grup 1 ve 2'de postoperatif kontinans değerlendirilmesi erken dönemde (sonda çekilmesini takiben) (\%58 ve $\% 31, \mathrm{p}=0.001), 1$. ayda (\%70 ve $\% 41, \mathrm{p}=0.002$ ) ve 3. ayda ( $\% 81$ ve $\% 60, \mathrm{p}=0.004)$ yapılmış ve kontinans oranları mesane boynu korunan (Grup 1) hastalarda anlamlı olarak daha iyi saptanmıştır. Postoperatif 6. ayda ise total kontinan hasta sayısı Grup 1 ve grup 2'de sirasiyla \%92 and \%82 olarak bulunmuştur $(\mathrm{p}=0.053)$.

\section{TARTIŞMA}

Mesane boynu, üriner kontinansı sağlamak amacıyla varolan kompleks üretral sfinkter mekanizmasının parçası olarak karşımıza çıkmaktadır. Üretral sfinkter dışta iskelet kası içte düz kastan oluşan, üreter orifislerinden membranöz üretraya dek uzanan ve 
Tablo 2. Peroperatif ve postoperatif hasta özellikleri. (NVD: Nörovasküler demet ADT: Androjen deprivasyon tedavisi).

\begin{tabular}{|c|c|c|c|}
\hline & Grup 1 & Grup 2 & $\mathbf{P}$ \\
\hline Cerrahi (konsol) süresi (dakika) & $154.2 \pm 36.1$ & $164.3 \pm 38.3$ & 0.164 \\
\hline Kan kaybı (cc) & $91.8 \pm 44.2$ & $103.7 \pm 58.1$ & 0.09 \\
\hline $\begin{array}{l}\text { NVD-koruyucu teknik: n (\%) } \\
\text { Uygulanmadı } \\
\text { Tek taraflı } \\
\text { Çift taraflı }\end{array}$ & $\begin{array}{l}20(\% 14.1) \\
32(\% 22.6) \\
89(\% 63.1) \\
\end{array}$ & $\begin{array}{c}6(\% 8.2) \\
14(\% 19.1) \\
53(\% 72.6) \\
\end{array}$ & \\
\hline Posterior rekonstrüksiyon (Rocco) sütürü, n (\%) & $16(\% 11.3)$ & $7(\% 9.6)$ & 0.694 \\
\hline Hastanede yatış süresi, gün & $4.01 \pm 1.4$ & $4.04 \pm 1.6$ & 0.87 \\
\hline Sonda çekilme süresi, gün & $8.6 \pm 2.6$ & $9.5 \pm 3.1$ & 0.04 \\
\hline $\begin{array}{l}\text { Perioperatif komplikasyon (0-30 gün) (Clavien-D } \\
\text { n (\%) } \\
\text { Grade } 1 \\
\text { Grade } 2 \\
\text { Grade } 3 \mathrm{a} \\
\text { Grade } 3 \mathrm{~b} \\
\text { Grade } 4 \\
\text { Grade } 5\end{array}$ & $\begin{array}{c}2(\% 1.4) \\
0(\% 0) \\
0(\% 0) \\
1(\% 0.7) \\
0(\% 0) \\
0(\% 0) \\
\end{array}$ & $\begin{array}{c}0(\% 0) \\
1(\% 1.3) \\
0(\% 0) \\
2(\% 2.7) \\
0(\% 0) \\
0(\% 0) \\
\end{array}$ & \\
\hline Postoperatif komplikasyonlar (30-90 gün), n (\%) & $0(\% 0)$ & $0(\% 0)$ & \\
\hline $\begin{array}{l}\text { Patolojik Gleason skorları, n (\%) } \\
3+3 \\
3+4 \\
4+3 \\
4+4 \\
3+5 \\
\geq 4+5\end{array}$ & $\begin{array}{c}54(\% 38.2) \\
46(\% 32.6) \\
17(\% 12) \\
6(\% 4.2) \\
4(\% 2.8) \\
13(\% 9.2) \\
\end{array}$ & $\begin{array}{c}32(\% 43.8) \\
22(\% 30.1) \\
9(\% 12.3) \\
3(\% 4.1) \\
0(\% 0) \\
6(\% 8.2) \\
\end{array}$ & \\
\hline $\begin{array}{l}\text { Pozitif cerrahi sınır, n (\%) } \\
\text { Toplam } \\
\text { pT2 } \\
\text { pT3 }\end{array}$ & $\begin{array}{c}43(\% 30.4) \\
14(\% 9.9) \\
29(\% 20.5) \\
\end{array}$ & $\begin{array}{c}19(\% 26.0) \\
6(\% 8.2) \\
13(\% 17.8) \\
\end{array}$ & 0.494 \\
\hline $\begin{array}{l}\text { Patolojik T evresi, n (\%) } \\
\text { pT0 } \\
\text { pT2 } \\
\text { pT3a } \\
\text { pT3b } \\
\text { pT4 }\end{array}$ & $\begin{array}{c}2(\% 1.4) \\
76(\% 53.9) \\
43(\% 30.4) \\
18(\% 12.7) \\
2(\% 1.4)\end{array}$ & $\begin{array}{c}1(\% 1.3) \\
47(\% 64.3) \\
14(\% 19.1) \\
11(\% 15) \\
0(\% 0)\end{array}$ & \\
\hline $\begin{array}{l}\text { Patolojik N evresi, n (\%) } \\
\text { pNx } \\
\text { pN0 } \\
\text { pN1 }\end{array}$ & $\begin{array}{c}0(\% 0) \\
138(\% 97.8) \\
3(\% 2.1) \\
\end{array}$ & $\begin{array}{c}0(\% 0) \\
68(\% 93.1) \\
5(\% 6.8) \\
\end{array}$ & \\
\hline Çıkarılan lenf nodu sayısı, n & $13 \pm 7.8$ & $14 \pm 4.7$ & 0.602 \\
\hline Biyokimyasal rekürrens n (\%) & $7(\% 4.9)$ & $3(\% 4.1)$ & \\
\hline Adjuvan ADT n (\%) & $5(\% 71.4)$ & $2(\% 66.6)$ & \\
\hline Adjuvan radyoterapi n (\%) & $2(\% 28.5)$ & $1(\% 33.3)$ & \\
\hline
\end{tabular}


Tablo 3. Hastaların postoperatif fonksiyonel sonuçları.

\begin{tabular}{|l|c|c|c|}
\hline & Grup 1 & Grup 2 & P değeri \\
\hline Kontinans, n (\%), takibi olan & $134(\% 100)$ & $51(\% 100)$ & 0.001 \\
\hline $\begin{array}{l}\text { Erken kontinans (sonda çekilmesini } \\
\text { takiben), } \mathrm{n}(\%)\end{array}$ & $78(\% 58)$ & $16(\% 31)$ & 0.002 \\
\hline 1.ay, $\mathrm{n}(\%)$ & $95(\% 70)$ & $21(\% 41)$ & 0.004 \\
\hline 3. ay, $\mathrm{n}(\%)$ & $109(\% 81)$ & $31(\% 60)$ & 0.053 \\
\hline 6. ay, $\mathrm{n}(\%)$ & $124(\% 92)$ & $42(\% 82)$ & $17(\% 100)$ \\
\hline $\begin{array}{l}\text { Potens (IIEF } \geq 21), \mathrm{n}(\%) \text { Preoperatif potent } \\
\text { hastalar }\end{array}$ & $43(\% 100)$ & $7(\% 41)$ & 0.708 \\
\hline 6 ay, $\mathrm{n}(\%)$ & $20(\% 46)$ & $10(\% 58)$ & 0.649 \\
\hline 12 ay, $\mathrm{n}(\%)$ & $28(\% 65)$ & \\
\hline
\end{tabular}

üretrayı çepeçevre saran bir yapıdır (13). Bu sfinkter yapısının korunarak kontinansa olumlu etki görülebileceği düşüncesi ile oluşturulan 'mesane boynu koruyucu teknik' ilk olarak 1992 yılında tanımlanmıştır (14). Mesane boynu koruyucu yaklaşım ile uygulanan açık radikal prostatektominin kanser kontrolünden ödün vermeksizin uygulanabildiğini gösteren (4-6) ve bunun tersi olarak cerrahi sinır pozitifliğine neden olabileceğini gösteren çalışmalar bulunmaktadır (8-9). Bellangino ve ark. yaptıkları derlemede mesane boynu koruyucu yaklaşımın özellikle prostat bazalinde cerrahi sınır pozitifliğini artırdığını saptamışlardır (15). Bizim çalışmamızda cerrahi sınır pozitifliği Grup l'de daha fazla olmakla birlikte iki grup arasında anlamlı fark saptanmamıştır ( $\mathrm{p}=0.494)$.

RARP sırasında taktil uyarının olmaması mesane boynu diseksiyonunu özellikle öğrenme sürecinde, en zorlu aşamalardan biri haline getirmektedir (16-17). Mesane boynu koruyucu RARP uygulanıp cerrahi s1nır pozitifliği, biyokimyasal rekürrens ve rezidü prostat dokusu kalan hastaların yüksek bulunduğu çalışmalarda bu duruma dikkat etmek gereklidir. Çalışmamızda öğrenme eğrisindeki hastaların çalışma dışı bırakılması bu dezavantajı ortadan kaldırmıs olup cerrahi sınır pozitifliği bu nedenle gruplar arasında benzer bulunmuş olabilir.

Kontinans ve erektil fonksiyon RARP sonrası en önemli fonksiyonel parametreler olarak karşımıza çıkmaktadır (18). Özellikle kontinansın erken kazanılması adına mesane boynu koruyucu teknikler önem kazanmış ve değişik teknikler tanımlanmıştır (19-20).
Bartoletti ve ark mesane boynu korunmadan RARP, tek başına mesane boynu koruyucu RARP, mesane boynu koruyucu yaklaşımla birlikte posterior rekonstrüksiyon uygulanan RARP ve retropubik radikal prostatektomi ve mesane boynu koruyucu yaklaşım uygulanan hastaların verilerini karşılaştırmış, RARP ile birlikte mesane boynu koruyucu yaklaşım ve posterior rekonstrüksiyon uygulanan hastaların, mesane boynu korunmadan RARP uygulanan hastalara ve retropubik radikal prostatektomi ve mesane boynu koruyucu yaklaşım uygulanan hastalara oranla ilk yıl daha iyi kontinans oranlarına sahip olduğunu göstermişlerdir (21). Çalışmamızda da mesane boynu koruyucu yaklaşım uygulanan hastaların her iki grupta da bir bölümüne posterior rekonstrüksiyon uygulanmış olup iki grup arasında anlamlı fark saptanmamıştır $(\mathrm{p}=0.694)$.

Çalışmamızdaki komplikasyon oranları diğer serilerle benzerlik göstermektedir (22). Mesane boynu kontraktürü veya üriner retansiyon gibi mesane boynu ile ilgili olabilecek komplikasyonlara Grup 1'de rastlanmamıştır.

Mesane boynu koruyucu RARP uygulanan hastalarda hastanede kalış ve transüretral sonda çekilme süresinin daha kısa olduğunu bildiren çalışmalar mevcuttur. Bu çalışmalarda mesane boynu korunmayan hastalar anastomoz kaçağı ve geç iyileşme ile ilişkili görünmektedir (13). Çalışmamızda gruplar arasında hastanede kalış sürelerinde anlamlı fark saptanmamakla birlikte, mesane boynu korunan hastalarda transüretral sonda çekilme süresinin daha kısa olduğu 
görülmüştür. Mesane boynunun korunması, mesane boynunun korunamamasına bağlı olabilecek anastomoz kaçağı ve buna sekonder gelișebilecek peritonit, ileus ve transüretral sondanın uzun süre kalmasına bağlı gelişebilecek üriner enfeksiyon gibi komplikasyonların önüne geçilmesini sağlayabilir.

Çalışmamızın bazı kısıtlılıkları mevcut olup bunlardan birincisi retrosektif tasarımı olmasıdır. İkincisi, çalışma 8 yıllık uzun bir periyod içindeki hastaları kapsamakta olup zaman içerisinde mesane boynu korunması için farklı cerrahi teknikler kullanılmıştır. Üçüncüsü ise hastaların operasyon öncesi kontinans durumlarını belirlemede preoperatif objektif bir kontinans durum değerlendirilmesi yapılmamıştır.

\section{SONUÇ}

Yeterli cerrahi deneyim kazanıldıktan sonra yapılan mesane boynu koruyucu RARP ameliyat, kanser kontrolünden ödün vermeksizin kontinansın erken kazanılmasında avantajlı görünmektedir. Ayrıca mesane boynu korunan hastalarda transüretral sondanın erken çekilmesi gelişebilecek komplikasyonlar açısından koruyucu olabilir.

\section{KAYNAKLAR}

1. Hu JC, Gu X, Lipsitz SR, Barry MJ, D’Amico AV, Weinberg AC, et al. Comparative effectiveness of minimally invasive vs open radical prostatectomy. JAMA 2009;302:1557-64.

2. Berryhill R Jr, Jhaveri J, Yadav R, Leung R, Rao S, El-Hakim A, et al. Robotic prostatectomy: a review of outcomes compared with laparoscopic and open approaches. Urology 2008;72:15- 23.

3. Piechaud T, Annino F. Bladder neck dissection during robotic assisted laparoscopic radical prostatectomy. In: John $\mathrm{H}$, Wiklund P, editors. Robotic urology. Berlin: Springer; 2013. p. 247-58

4. Shelfo SW, Obek C, Soloway MS. Update on bladder neck preservation during radical retropubic prostatectomy: impact on pathologic outcome, anastomotic strictures, and continence. Urology 1998;51:73-8.

5. Deliveliotis C, Protogerou V, Alargof E, Varkarakis J. Radical prostatectomy: bladder neck preservation and puboprostatic ligament sparing-effects on continence and positive margins. Urology 2002;60:855-8.

6. Braslis KG, Petsch M, Lim A, Civantos F, Soloway MS. Blad- der neck preservation following radical prostatectomy: continence and margins. Eur Urol 1995;28:202-8.

7. Selli C, De Antoni P, Moro U, Macchiarella A, Giannarini $G$, Crisci A. Role of bladder neck preservation in urinary.

8. Srougi M, Nesrallah LJ, Kauffmann JR, Nesrallah A, Leite KR. Urinary continence and pathological outcome after bladder neck preservation during radical retropubic prostatectomy: a randomized prospective trial. J Urol 2001;165: 815-18. 13

9. Marcovich R, Wojno KJ, Wei JT, Rubin MA, Montie JE, Sanda MG. Bladder neck-sparing modification of radical prostatectomy adversely affects surgical margins in pathologic T3a prostate cancer. Urology 2000;55:904-8.

10. Rosen RC, Cappelleri JC, Smith MD, et al. Development and evaluation of an abridged, 5-item version of the International Index of Erectile Function (IIEF-5) as a diagnostic tool for erectile dysfunction. Int J Impot Res 1999;11: 319-326.

11. Dindo D, Demartines N, Clavien PA. Classification of surgical complications: a new proposal with evaluation in a cohort of 6336 patients and results of a survey. Ann Surg 2004;240:205-213.

12. Canda AE, Atmaca AF, Akbulut Z, Asil E, Kilic M, et al. Results of robotic radical prostatectomy in the hands of surgeons without previous laparoscopic radical prostatectomy experience. Turk J Med Sci. 2012;42(Suppl 1):1338-46.

13. Koraitim MM. The male urethral sphincter complex revisited: an anatomical concept and its physiological correlate. J Urol 2008;179:1683-9.

14. Klein EA. Early continence after radical prostatectomy. J Urol 1992;148:92-5.

15. Mariangela Bellangino, Clare Verrill, Tom Leslie, Richard W. Bell, Freddie C. Hamdy, Alastair D. Lamb. Systematic Review of Studies Reporting Positive Surgical Margins After Bladder Neck Sparing Radical Prostatectomy. Curr Urol Rep. 2017 Nov 7;18(12):99. doi: 10.1007/s11934-017-0745-0.

16. Tewari AK and Rao SR: Anatomical foundations and surgical manoeuvres for precise identification of the prostatovesical junction during robotic radical prostatectomy. BJU Int 2006; 98: 833.

17. Bird VG, Reese J and Winfield HN: Identification and dissection of bladder neck during laparoscopic radical prostatectomy. Urology 2002; 60: 680.

18. Acar C, Schoffelmeer CC, Tillier C, et al. Quality of life in patients with low-risk prostate cancer. A comparative retrospective study: Brachytherapy versus robot-assisted laparoscopic prostatectomy versus active surveillance. J Endourol 2014;28:117-124.

19. Lutfi Tunc, Huseyin Gumustas, Yigit Akin, Sinan Atkin, 
Tuncay Peker, Ozlem Erdem, Ibrahim Bozkirli. A Novel Surgical Technique for Preserving the Bladder Neck During Robot-Assisted Laparoscopic Radical Prostatectomy: Preliminary Results. J Endourol. 2015 Feb;29(2):186-91. doi: 10.1089/end.2014.0459. Epub 2014 Sep 5.

20. Lee Z, Sehgal SS, Graves RV, et al. Functional and oncologic outcomes of graded bladder neck preservation during robotassisted radical prostatectomy. J Endourol 2014;28:48-55.

21. Riccardo Bartoletti, Andrea Mogorovich, Francesco Francesca, Giorgio Pomara, Cesare Selli. Combined bladder neck preservation and posterior musculofascial reconstruction during robotic assisted radical prostatectomy: effects on early and long term urinary continence recovery. BMC Urol. 2017 Dec 15;17(1):119. doi: 10.1186/s12894-0170308-1.
22. Tewari A, Sooriakumaran P, Bloch DA, et al. Positive surgical margin and perioperative complication rates of primary surgical treatments for prostate cancer: A systematic review and meta-analysis comparing retropubic, laparoscopic, and robotic prostatectomy. Eur Urol 2012;62:1-15.

23. David F. Friedlander, Mehrdad Alemozaffar, Nathanael D. Hevelone, Stuart R. Lipsitz and Jim C. Hu. Stepwise Description and Outcomes of Bladder Neck Sparing During RobotAssisted Laparoscopic Radical Prostatectomy. J Urol. 2012 Nov;188(5):1754-60. doi: 10.1016/j.juro.2012.07.045. Epub 2012 Sep 19. 